\title{
METODOLOGIAS ATIVAS: O PROTAGONISMO DO DISCENTE NO PROCESSO DE APRENDIZAGEM
}

\author{
Suellen Galvão Moraes ${ }^{(\mathrm{a})}$, Márcia Thelma Rios Donato Marino ${ }^{(\mathrm{b})}$ Denise Fernandes ${ }^{(\mathrm{c})}$ Matheus \\ Cordeiro Façanha ${ }^{(d)}$ \\ (a) Especialista, UNIFOR - Universidade de Fortaleza. suellengalvao_m@ @otmail.com \\ (b) Docente, UNIFOR - Universidade de Fortaleza. marino@unifor.br \\ (c) Docente, UNIFOR - Universidade de Fortaleza. denisefernandes@unifor.br \\ (d) Graduando, UNIFOR - Universidade de Fortaleza. matheuscordeiro@edu.unifor.br
}

\section{EIXO: GEOGRAFIA FÍSICA: CURRÍCULO, FORMAÇÃO E PRÁTICAS DE ENSINO}

\begin{abstract}
Resumo
Esta pesquisa apresenta a percepção dos discentes da disciplina Ecossistemas Marinhos e Ambientes Costeiros, acerca da relação teoria versus aprendizagem com a utilização de metodologias ativas, para proposição de medidas que melhorem a aprendizagem da disciplina. Trata-se de estudo com abordagem quantitativa e análise descritiva. Os dados foram coletados por meio de um questionário semiestruturado, aplicado junto aos alunos Engenharia Ambiental e Sanitária, da Universidade de Fortaleza (UNIFOR). Diferentes formas de uso e aplicação de metodologias ativas foram analisadas, buscando-se qual a eficácia das mesmas no processo de aprendizagem e aplicabilidade dos conhecimentos. O estudo possibilitou a confirmação da importância e necessidade do uso de diversas metodologias ativas de ensino-aprendizagem, sobretudo aquelas que requerem o protagonismo do aluno no seu saber, bem como, um direcionamento para a condução da disciplina para os próximos semestres.
\end{abstract}

Palavras-chave: Monitoria acadêmica. Ecossistemas marinhos. Ambientes costeiros

\section{Introdução}

O Curso Superior de Engenharia Ambiental e Sanitária é novo no país e sua matriz curricular passa por algumas alterações, de acordo com as demandas e contextos da atualidade. A disciplina Ecossistemas Marinhos e Ambientes Costeiros é parte integrante do $2^{\circ}$ semestre desse curso, na Universidade de Fortaleza (UNIFOR). Apresenta-se como de relevante interesse e necessidade, visto que estamos localizados geograficamente numa região litorânea e, como a grande maioria das áreas costeiras do Planeta, sofre muito com seus diversos usos e explorações, além de ser um ecossistema rico e de grande sensibilidade ambiental e social.

A zona costeira apresenta grande importância em termos socioeconômicos e ambientais, sendo caracterizada como um ambiente dinâmico e frágil frente a esses processos, fato que a coloca, atualmente, em constantes situações de risco, tornando-a um objeto de estudo que aborda a multidisciplinaridade de áreas científicas preocupadas com o seu desenvolvimento de forma sustentável. 


\section{OS DESAFIOS DA GEOGRAFIA FÍSICA NA FRONTEIRA DO CONHECIMENTO \\ Instituto de Geociências - Unicamp \\ Campinas - SP \\ 28 de Junho à 02 de Julho de 2017}

Tendo em vista a relevância socioambiental desses ambientes, iniciativas que promovam o conhecimento técnico e científico com fins de buscar solucionar problemas que se apresentam, mas também de evitar futuros impactos a esses ambientes, são de grande importância para a sustentabilidade desses ambientes. Para tanto, os usos de diversas metodologias de ensino podem e devem ser aplicados pelo docente, a fim de apresentar ao aluno múltiplas ferramentas de aprendizagem, muitas das quais ele mesmo será o protagonista do seu conhecimento. Tais métodos são conhecidos como Metodologias Ativas.

De acordo com Weisz (2004):

O aprendiz é um sujeito protagonista no seu próprio processo de aprendizagem, alguém que vai produzir a transformação que converte em informação em conhecimento próprio. Essa construção pelo aprendiz não se dá por si mesma e no vazio, mas a partir de situações nas quais ele possa agir sobre o objeto de seu conhecimento, pensar sobre ele recebendo ajuda, sendo desafiado a refletir. (WEISZ, 2004, p. 60).

O processo de empoderamento do conhecimento, a partir de sua construção pelo próprio aluno, acaba sendo em si, um processo de aprender a aprender, inclusive para o professor, que por vezes é proveniente de uma escola pedagógica tradicionalista. Dessa forma o próprio professor também precisa motivar-se na busca por essa nova forma de ensinar-aprender. Por sua vez o aluno, muitas vezes produto de uma escola também tradicionalista, está habituado a receber informação do professor e não a buscar e processá-la visando uma aplicação profissional, em se tratando do ensino superior.

Moran (2015, p. 15) em seu relato "Mudando a Educação com Metodologias Ativas" descreve:

As instituições educacionais atentas às mudanças escolhem fundamentalmente dois caminhos, um mais suave - mudanças progressivas - e outro mais amplo, com mudanças profundas. No caminho mais suave, elas mantêm o modelo curricular predominante disciplinar - mas priorizam o envolvimento maior do aluno, com metodologias ativas como o ensino por projetos de forma mais interdisciplinar, o ensino híbrido ou blended e a sala de aula invertida. Outras instituições propõem modelos mais inovadores, disruptivos, sem disciplinas, que redesenham o projeto, os espaços físicos, as metodologias, baseadas em atividades, desafios, problemas, jogos e onde cada aluno aprende no seu próprio ritmo e necessidade e também aprende com os outros em grupos e projetos, com supervisão de professores orientadores.

Em vista da relevância da análise das metodologias ativas ensino-aprendizagem (seminários, aulas de campo/visitas técnicas, dinâmicas e trabalhos em grupo), dentre outras práticas utilizadas no meio universitário, este estudo objetivou conhecer a percepção dos discentes da disciplina Ecossistemas Marinhos e Ambientes Costeiros, acerca da relação Teoria x Aprendizagem com a utilização de metodologias ativas, relatada pela monitoria.

Segundo Winkler et al. (2009, p.2), "o processo de ensino-aprendizagem compreende um conjunto de ações que envolvem pessoas, técnicas e instrumentos cujo objetivo é a construção de um conhecimento 
para aqueles indivíduos que não o dominam”. Trata-se, desta forma, da efetiva construção e não de mera transferência destes conhecimentos para uma plateia ávida por informações.

\section{Metodologia}

$\mathrm{O}$ estudo possui cunho científico acadêmico, trata-se de uma pesquisa com abordagem quantitativa e análise descritiva. A composição da fundamentação teórica, em gabinete, foi pautada na avaliação do material bibliográfico para formação do banco de dados, por meio de análise de revisões de literatura em produções acadêmicas, livros, publicações e documentos referentes às temáticas investigadas.

Os dados foram coletados por intermédio de observações, entrevistas semidirigidas (conversas informais e relatos) e mediante aplicação de questionário submetido à avaliação do Comitê de Ética sob CAAE $\mathrm{n}^{\circ}$. 58871016.9.0000.5052, durante os meses de Maio, Junho e Novembro de 2016. Trabalhou-se com uma amostra estratificada, distribuída entre discentes da disciplina, perfazendo uma população de 70 alunos. Foram entrevistados 67 alunos, entre adultos dos sexos masculino e feminino, maiores de 18 (dezoito) anos, considerando um nível de confiança de $99 \%$ e erro amostral de $4 \%$. Para uma significativa análise quantitativa e visualização dos resultados, os dados foram tabulados no programa Excel@Microsoft, gerando gráficos e tabelas, e analisados considerando-se uma escala de 0-5 (0 - Ineficiente; 5 - Muito Alta), quanto à eficácia da metodologia pelos alunos.

\section{Resultados e discussão}

Metodologias de ensino padronizadas requerem resultados padronizados. Porém, padrões como resultados de ensino-aprendizagem no contexto atual, já não são tão bem aceitos como nos séculos passados. O mercado de trabalho exige cada vez mais um profissional com multi-habilidades e que saiba trabalhar com diversas ferramentas, além de uma visão interdisciplinar.

Para tanto, a educação superior precisa se adaptar às mudanças que vem ocorrendo com cada vez mais celeridade no mundo tecnológico, onde a informação e o saber estão à mão com facilidade, favorecendo muitas vezes, a um julgamento precipitado, onde a figura do Professor Educador poderia ser deixada em segundo plano. Entretanto, a condução do uso dessas informações pode e deve ser mediada pelo Educador. As tecnologias não precisam ser vistas como uma ameaça à relevância do Professor em sala de aula e sim como um advento, tendo em vista a infinidade de possibilidades a serem exploradas e introduzidas como ferramentas metodológicas, didáticas e pedagógicas dentro e fora de sala de aula. 
Desta feita, optou-se por utilizar, dentro da disciplina de Ecossistemas Marinhos e Ambientes Costeiros, algumas ferramentas de ensino aprendizagem que buscam uma participação plural do aluno na construção do seu conhecimento teórico, com vistas à aplicabilidade prática, a saber: a) aula expositiva com slides pelo professor; b) apresentação de documentários; c) aula de campo/visita técnica; d) palestras com resumos; e) apresentação de seminários pelos alunos; f) leitura e discussão de notícias atuais sobre a temática; e g) elaboração de artigo científico.

Por se tratar de uma disciplina que não apresenta um perfil lógico próprio dos cursos de Engenharia, podese imaginar que a adoção de tais práticas pedagógicas não sejam tão relevantes para o aprendizado do aluno. Porém, tendo em vista a pluralidade intrínseca aos ambientes naturais, sobretudo os da zona costeira, a compreensão dos conceitos e padrões abordados, análises situacionais da realidade ambiental são extremamente importantes para um processo efetivo da aprendizagem.

Essa disciplina tem sua aplicação extremamente prática, sobretudo para a região geográfica em que estamos localizados, uma área litorânea, que por sua vez, compreende diversos fatores antrópicos e naturais que costuram sua complexidade na gestão dos múltiplos usos, mitigação e prevenção de impactos.

A Figura 1 ilustra um panorama geral dessas metodologias e sua eficácia de aprendizado frente aos discentes. Percebe-se que dentre as metodologias adotadas, a que apresentou melhor eficácia foi a "Aula de campo ou Visita técnica", $75 \%$ dos alunos consideraram Muito Alto o nível de aproveitamento. Em seguida, com 55\% de máxima aceitação, registra-se o método "Leitura e discussão de notícias atuais sobre a temática", atividade em que os alunos são orientados a pesquisarem notícias relevantes sobre os assuntos abordados e, espontaneamente, cada um relata sua pesquisa, acompanhada por uma breve discussão do que foi exposto entre os discentes, sendo comentada e complementada pelo professor.

"Elaboração de artigos científicos" aparece logo em seguida com 51\%, 27\%, 12\%, 4\%, 1\% e 1\% para Muito Alto, Alto, Moderado, Baixo, Muito Baixo e Ineficiente, respectivamente e apresenta níveis de homogeneidade entre as categorias bem similares à metodologia de "Leitura e discussão de notícias atuais".

Em quarta posição está "Apresentação de documentários em sala de aula", onde 46\% dos alunos julgaram ter nível Muito Alto de eficácia no seu aprendizado e 24\% consideram Alto.

"Apresentação de seminários pelos alunos", obteve certa homogeneidade entre Muito Alto e Alto (37\% e $34 \%$ respectivamente) quanto ao nível de eficácia, porém, considera-se um quantitativo baixo de alunos interessados nessa metodologia. 

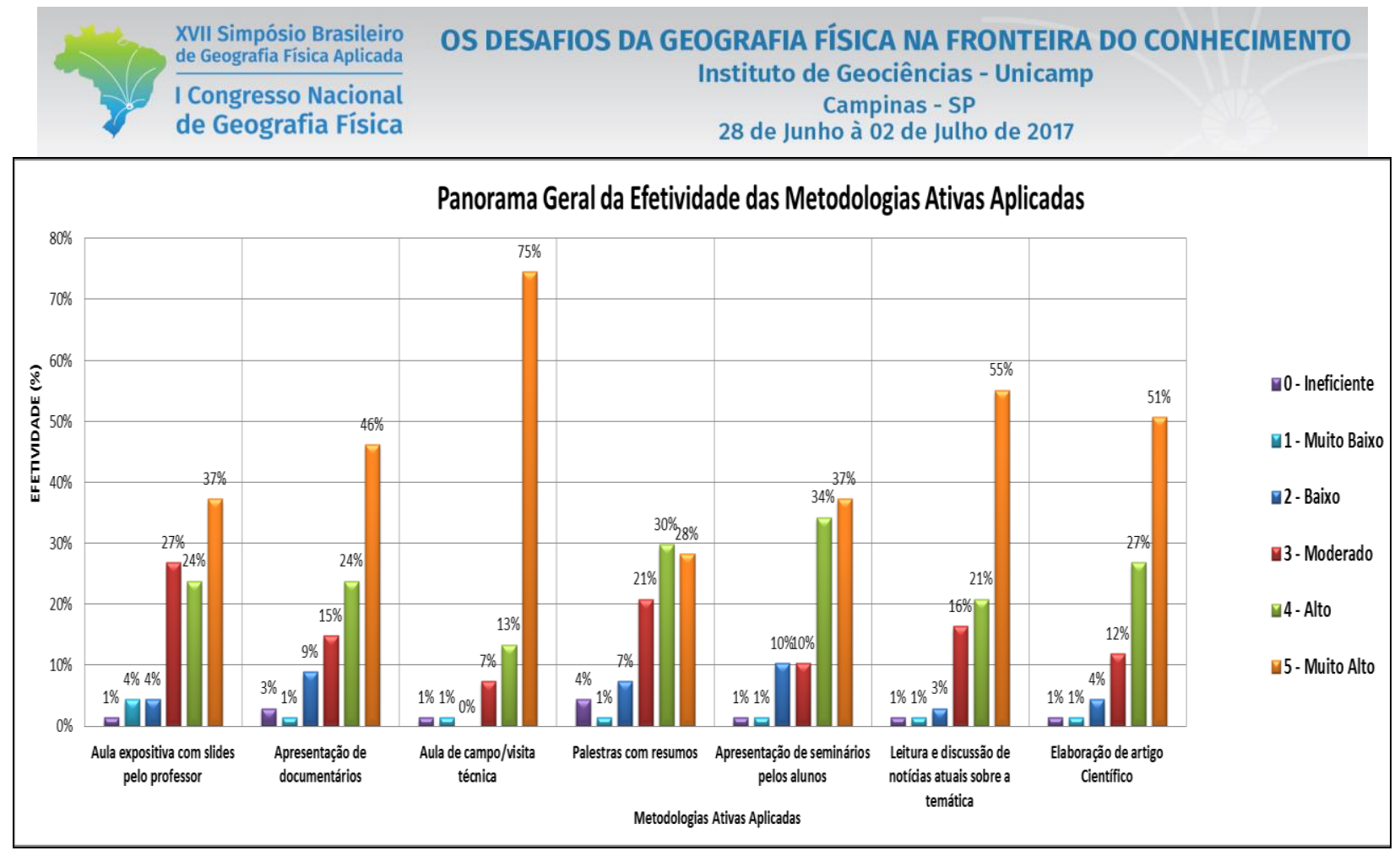

Figura 1 - Panorama geral da efetividade das metodologias ativas aplicadas.

Em quinto lugar com nível Muito Alto (37\%) está a “Aula expositiva com slides pelo professor", seguido de $24 \%$ alto e $27 \%$ Moderado.

A metodologia que apresentou resultados menos eficientes foi "Palestras com resumos", na qual 28\% consideram Muito Alto e 30\%, 21\%, 7\%, 1\% e 4\%, respectivamente, apresentam níveis Alto, Moderado, Muito Baixo, Baixo e Ineficiente. Em nenhuma outra metodologia se atingiu esse mesmo nível para Ineficiente. Acredita-se que a forma de aplicação deva ser modificada, pois muitas vezes o aluno não participa efetivamente dessas palestras, desenvolvendo os seus resumos por meio de pesquisas bibliográficas, perdendo a rica discussão e interação com os palestrantes, profissionais renomados dentro dos contextos abordados.

\section{Conclusão}

O uso de diversas Metodologias Ativas e a prática da Monitoria para a disciplina de Ecossistemas Marinhos e Ambientes Costeiros, mostraram-se ferramentas bastante eficientes.

Quanto às metodologias adotadas, percebe-se uma preferência bem maior por "Aulas de Campo ou Visitas Técnicas", oportunidade em que o discente pode visualizar e sentir o que significa toda a teoria vista em sala de aula pelo professor. Entretanto, sabe-se que em virtude de vários fatores de ordem administrativa, pedagógica e logística, não seja possível, muitas vezes, a realização de mais de um evento desse tipo por semestre, ressaltando que esta disciplina consta apenas de créditos teóricos. 
Porém, pode-se pensar em alternativas que requeiram do próprio aluno o protagonismo do seu saber, solicitando, que a seu tempo e disposição, o mesmo possa ir à campo levantar dados por meio de observações coletadas e apresentá-las em momento oportuno em sala de aula, seja em grupo ou individualmente.

Já a metodologia "Elaboração de Resumos de Palestras" pode ser repensada sua aplicabilidade, podendo substituir o "Resumo" por uma "Roda de Conversa" posteriormente ao Evento, a fim de buscar um maior aproveitamento quanto ao aprendizado.

As três metodologias que apresentaram os melhores resultados na pesquisa, foram justamente as que envolvem a saída de sala de aula para o aprendizado (Aula de Campo/Visita técnica) e as que requerem do aluno estudante o protagonismo de seu aprendizado, onde ele deve buscar, construir e reconstruir o conhecimento a partir da pesquisa, escrita e diálogo com seus pares e docente, mesmo que em sala de aula, forma esses: "Leitura e discussão de notícias atuais" e "Elaboração de artigo científico".

Esse estudo possibilitou a confirmação da importância e necessidade do uso de diversas metodologias ativas de ensino-aprendizagem, bem como um direcionamento para a condução da disciplina para os próximos semestres, no intuito de buscar a melhoria contínua na produção do saber e desenvolvimento.

\section{Agradecimentos}

Os autores agradecem aos programas de Iniciação à Pesquisa PIBIC/CNPq, PAVIC/UNIFOR e ao Programa de Monitoria Voluntária (PROMOV) da Universidade de Fortaleza (UNIFOR).

\section{REFERÊNCIAS}

MORAN, J. M. Mudando educação com metodologias ativas. In: SOUZA, C. A. de; MORALES, O. E. T. (orgs.). Coleção Mídias Contemporâneas. Convergências Midiáticas, Educação e Cidadania: aproximações jovens. Vol. II. Ponta Grossa: Foca Foto-PROEX/UEPG, 2015. Disponível em:< http://www2.eca.usp.br/moran/wpontent/uploads/2013/12/mudando_moran.pdf>. Acessado em: 07 de agosto de 2016.

WEISZ, T. O diálogo entre o ensino e a aprendizagem. 2 ed. São Paulo: Ática, 2004.

WINKLER, I. ABREU, J. C. A. DE MORAIS, K. S. DE; SILVA, L. P. PINHO, J. A. G. DE. O processo ensinoaprendizagem em uma disciplina de administração: percepções de docentes e discentes. In: Anais do encontro da Associação Nacional de Pós-graduação e pesquisa em administração, 33, São Paulo, 2009. 